\title{
ANALISIS KREATIVITAS MATEMATIS SISWA SMA MELALUI \\ PROJECT BASED LEARNING TERINTEGRASI STEM PADA PEMBELAJARAN FISIKA ELASTISITAS DI KELAS XI MIPA 6 SMAN 2 JEMBER
}

\author{
${ }^{1)}$ Nuri Ade Iksani Devi, ${ }^{1)}$ Albertus Djoko Lesmono, ${ }^{2)}$ Heni Mulyo Widodo \\ ${ }^{1)}$ Program Studi Pendidikan Fisika FKIP Universitas Jember \\ ${ }^{2)}$ SMAN 2 Jember \\ Email: nuriadeiksanidevi@gmail.com
}

\begin{abstract}
This study examines STEM (Science, Technology, Engineering, and Mathematics) as one approach that is integrated with the project based learning model. This study aims to analyze the mathematical creativity of high school students through the integrated STEM project based learning model in learning physics material elasticity. The research method used was a pre-experimental design with the One Group Post-test Only Design which was carried out in class XI MIPA 6 of SMAN 2 Jember with 36 students consisting of 14 male students and 22 female students formed in 6 heterogeneous groups each - each group consisted of 6 people. Data collection was performed using the final test in the form of analysis of student worksheets and video analysis of student learning processes to measure students' mathematical creativity. Based on the results of the study, it was found that the application of STEM integrated project based learning affected the mathematical creativity of high school students in class XI MIPA 6 of SMAN 2 Jember.
\end{abstract}

Keywords: STEM, project based learning, mathematical creativity.

\section{PENDAHULUAN}

STEM (Science, Technology, Engineering, and Mathematics) diluncurkan pada tahun 1990-an oleh National Science Foundation AS sebagai tema gerakan reformasi pendidikan dalam keempat bidang disiplin tersebut untuk menumbuhkan angkatan kerja di bidang STEM, dan meningkatkan daya saing global AS dalam inovasi IPTEK (Hanover Research, 2011). Adanya gerakan reformasi pendidikan STEM ini karena laporan-laporan studi menunjukkan terjadinya kekurangan tenaga kerja di bidang STEM (Roberts, 2012). Pendidikan STEM berpeluang bagi guru untuk menujukkan kepada peserta didik bahwa konsep, prinsip, dan teknik dari sains, teknologi, engineering, dan matematika digunakan secara terintegrasi dalam pengembangan produk, proses, dan sistem yang diterapkan dalam kehidupan sehari-hari. Oleh karena itu, Reeve (2013) mengadopsi definisi STEM sebagai pendekatan interdisiplin pada pembelajaran, yang mana peserta didik menggunakan sains, teknologi, enjiniring, dan matematika dalam konteks nyata yang menghubungkan antara sekolah, dunia kerja, dan dunia global, sehingga peserta didik mampu bersaing dalam era globalisasi berbasis pengetahuan.

Dalam menghadapi era persaingan global, Indonesia juga perlu mempersiapkan Sumber Daya Manusia (SDM) yang handal dalam keempat bidang disiplin (STEM) tersebut, baik secara kualitas maupun secara 
kuantitas. Berdasarkan data Badan Pusat Statistik 2010, SDM Indonesia masih didominasi tenaga kerja kurang terampil (sebanyak 88 juta), dan diprediksi 2020 akan ada 50\% kekurangan tenaga kerja dalam jabatan di struktur lapangan kerja. Permasalahan kualitas dan kuantitas SDM Indonesia yang berdaya saing global ini tidak dapat diatasi dengan Kurikulum 2013 (K-13), jika tidak secara sistematik menyiapkan mereka untuk mengembangkan pengetahuan, keterampilan dan sikap yang dipersyaratkan dunia kerja Abad-21, sebagaimana diwujudkan dalam pendidikan STEM. Meskipun K-13 bertujuan mempersiapkan manusia Indonesia agar mampu hidup sebagai pribadi dan warga negara yang beriman, produktif, kreatif, inovatif, dan afektif, serta mampu berkontribusi pada kehidupan bermasyarakat, berbangsa, bernegara, dan peradaban dunia. Maka, K-13 memberi ruang bagi pengembangan dan implementasi STEM dalam konteks implementasi Kurikulum 2013 (Kemendikbud, 2013).

STEM dapat diintegrasikan dengan model Project Based Learning (PjBL). Langkah-langkah pembelajaran dari PjBL terintegrasi STEM yaitu: mengemukakan dan menentukan masalah, menentukan pengerjaan proyek baik secara invidu atau kelompok, mengembangkan desain pemecahan masalah, membangun, menguji coba, dan mengevaluasi produk, serta mempresentasikan produk tersebut (Farwati et al., 2017). Berdasarkan hasil penelitian Tseng et al (2013) menyatakan bahwa $\mathrm{PjBL}$ terintegrasi STEM mampu meningkatkan minat belajar siswa, membantu siswa memecahkan masalah dalam kehidupan nyata, pembelajaran jadi lebih bermakna, dan menunjang karir masa depan. Selain itu, PjBL terintegrasi STEM memberi tantangan dan memotivasi siswa karena melatih mereka untuk berpikir kritis, analisis, dan meningkatkan keterampilan berfikir tingkat tinggi (Capraro et al., 2013).

Pembelajaran menggunakan model Project Based Learning terintegrasi STEM ini sangat cocok digunakan dalam pembelajaran fisika. Fisika merupakan bagian dari sains (IPA) yang hakikatnya sebagai kumpulan pengetahuan, cara berpikir, dan penyelidikan, dimana IPA sebagai kumpulan pengetahuan yang dapat berupa fakta, konsep, prinsip, hukum, teori, dan model (Astuti, 2012:70). Fisika dipandang sebagai suatu proses dan sekaligus produk, sehingga harus mempertimbangkan model pembelajaran yang efektif dan efisien, salah satunya yaitu melalui Project Based Learning terintegrasi STEM.

Model Project Based Learning terintegrasi STEM merupakan salah satu model pembelajaran fisika yang dianggap sesuai dengan perubahan tatanan kehidupan dunia pada Era globalisasi saat ini. Berdasarkan perubahan tatanan tersebut, kreativitas menjadi salah satu hal yang dapat menentukan keunggulan seseorang. Menurut Alexander (2007), kesuksesan seseorang ditentukan oleh kemampuan kreatifnya dalam menyelesaikan masalah, baik skala besar maupun kecil. Maka dari itu penting sekali untuk melatih kreativitas siswa, termasuk juga kreativitas dalam kemampuan matematis siswa. Hal ini sesuai dengan amanat kurikulum yang menyatakan bahwa, standar 
kompetensi lulusan siswa pada level SMA/SMK diantaranya yaitu memiliki kemampuan berpikir dan bertindak kreatif, produktif, kritis, mandiri, kolaboratif, dan komunikatif (Kemendikbud, 2016).

Berdasarkan latar belakang tersebut, maka penelitian bertujuan untuk menganalisis Kreativitas Matematis Siswa SMA Melalui Project Based Learning Terintegrasi STEM pada Pembelajaran Fisika Elastisitas di Kelas XI MIPA 6 SMA Negeri 2 Jember"

\section{METODE PENELITIAN}

Jenis penelitian yang dilakukan merupakan penelitian pra-eksperimen tipe deskriptif dengan desain One Shot Case Study (Sugiyono, 2008). Karena tidak ada kelas kontrol, dan hanya ada satu variabel yang ingin dianalisis yaitu kreativitas matematis. One Shot Case Study merupakan eksperimen yang hanya dilakukan pada satu kelompok saja tanpa adanya kelompok pembanding.

Penelitian ini bertujuan untuk menganalisis kreativitas matematis siswa SMA melalui model Project Based Learning (PjBL) terintegrasi STEM pada pembelajaran fisika materi elastisitas. Subyek atau sampel dalam penelitian ini adalah siswa kelas XI MIPA 6 di SMAN 2 Jember tahun pelajaran 2019/2020 yang dipilih dengan teknik purposive sampling yaitu penetapan responden untuk dijadikan sampel berdasarkan kriteriakriteria tertentu (Siregar, 2013). Jadi, penelitian ini terdiri dari satu kelas eksperimen yang mendapatkan sebuah perlakuan, yaitu diberikan pembelajaran dengan model Project Based Learning terintegrasi STEM (Science, Technology, Engineering, and Mathematics). Dalam penelitian ini, siswa tidak diberikan soal pre-test apapun sebelum diberi perlakuan, namun siswa diberi soal post-test setelah diberi perlakuan berupa Lembar Kerja Siswa (LKS) berbasis STEM untuk mengetahui kreativitas matematis siswa dalam memecahkan masalah fisika terutama pada materi elastisitas.

Berikut merupakan Gambar 1 berisi desain penelitian One Shoot Case Study.

$$
\text { Gambar 1. Desain One Shot Case Study }
$$

Desain penelitian One Shot Case Study Keterangan:

$\mathrm{X}$ : Perlakukan yang diberikan kepada siswa yaitu diajarkan dengan menggunakan model Project Based Learning (PjBL) terintegrasi STEM.

O : Kreativitas Matematis Siswa yang dilihat dari jawaban matematis siswa pada LKS berbasis STEM (LKS yang diberi setelah pembelajaran dengan model PjBL terintegrasi STEM).

(Jaedun, 2011: 10).

Penelitian ini dilaksanakan di kelas XI MIPA 6 SMAN 2 Jember dengan 36 siswa yang terdiri dari 14 siswa laki-laki dan 22 siswa perempuan di bentuk dalam 6 kelompok secara heterogen yang masing-masing kelompok terdiri dari 6 orang.

Prosedur penelitian yang dilakukan meliputi 3 tahap, yaitu: tahap perencanaan, tahap pelaksanaan, dan tahap akhir. Pada tahap perencanaan meliputi observasi pada 
lokasi penelitian untuk mendapatkan sampel penelitian dan lalu menetapkan kelompok studi (kelas) penelitian, konsultasi dengan guru bidang studi Fisika di SMAN 2 Jember mengenai metode dalam proses pembelajaran yang akan dilaksanakan, membuat Rencana Pelaksanaan Pembelajaran (RPP) dan Lembar Kerja Siswa (LKS) PjBL STEM tentang materi elastisitas. Tahap pelaksanaan yaitu memberi siswa perlakuan pembelajaran $\mathrm{PjBL}$ terintegrasi STEM. Tahap akhir yaitu mengukur variabel efek, menganalisis data, pembahasan, dan menarik kesimpulan. Berikut ini Gambar 2 menunjukkan alur penelitian.

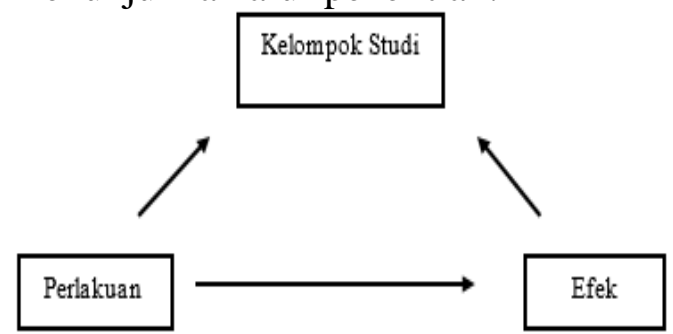

Gambar 2. Alur Penelitian

Instrumen yang digunakan adalah Lembar kerja Siswa (LKS) berbasis STEM dan video diskusi siswa dengan kelompoknya masingmasing selama proses pembelajaran.

Analisis data dalam penelitian ini dilakukan secara inferensial terhadap data kuantitatif. Data tersebut berupa jawaban matematis siswa dalam memecahkan masalah pada Lembar Kerja Siswa berbasis (LKS) STEM, dan analisis video diskusi siswa dengan kelompoknya masing-masing selama proses pembelajaran. Data yang diperoleh nantinya akan digunakan untuk menganalisis kreativitas matematis siswa. Pengujian Statististik menggunakan bantuan software SPSS (Statistik Product and Servis Solution) for windows v.23.0.
Teknik analisis data atau pengujian hipotesis dalam penelitian ini yaitu statitistik deskriptif yang dilakukan dengan uji t satu pihak One Shot Case Study yang dibandingkan dengan KKM SMAN 2 Jember, yaitu aspek kognitif, psikomotorik, dan afektif mata pelajaran fisika sebesar 80. Hipotesis yang diajukan yaitu: ratarata kreativitas matematis siswa kelas XI MIPA 6 SMAN 2 Jember lebih dari atau sama dengan 80 .

\section{HASIL DAN PEMBAHASAN}

Berdasarkan hasil analisis data dari jawaban siswa di LKS berbasis STEM dan analisis video diskusi siswa dengan kelompoknya masing-masing selama pembelajaran dapat dilihat pada Tabel 1 yang menggambarkan secara umum untuk kreativitas matematis siswa kelas XI MIPA 6 di SMA Negeri 2 Jember.

Tabel 1. Rekapitulasi Kreativitas

\begin{tabular}{lc}
\hline Komponen & Kreativitas Matematis \\
\hline Rata-rata & 83,33 \\
Nilai tertinggi & 95,00 \\
Nilai terendah & 60,00 \\
Kategori & baik \\
\hline
\end{tabular}

Berdasarkan analisis data diketahui bahwa, nilai tertinggi kreativitas matematis siswa yaitu 95, nilai terendah yaitu 60 , dan rata-rata kreativitas matematis siswa kelas XI MIPA 6 di SMAN 2 Jember yaitu 83,33 berada dalam kategori baik.

Tahap selanjutnya yaitu pengujian hipotesis satu sampel dengan uji t satu pihak. Uji t tersebut digunakan untuk menguji bahwa ratarata kreativitas matematis siswa kelas XI MIPA 6 SMA Negeri 2 Jember lebih dari atau sama dengan 80 . 
Rekapitulasi uji hipotesis dapat dilihat pada Tabel 2.

Tabel 2. Rekapitulasi Uji Hipotesis One-Sample Kolmogorov-Smirnov Test

\begin{tabular}{|ll|r|}
\hline & & \multicolumn{1}{c|}{$\begin{array}{c}\text { Kreativitas } \\
\text { Matematis }\end{array}$} \\
\hline $\mathrm{N}$ & 6 \\
Normal Parameters $^{\mathrm{a}, \mathrm{b}}$ & Mean \\
& $\begin{array}{l}\text { Std. } \\
\text { Devia } \\
\text { tion }\end{array}$ & 12.51666 \\
Most Extreme & $\begin{array}{l}\text { Absol } \\
\text { ute } \\
\text { Differences }\end{array}$ & $\begin{array}{l}\text { Positi } \\
\text { ve } \\
\text { Negat } \\
\text { ive }\end{array}$ \\
Test Statistic & .228 \\
Asymp. Sig. (2-tailed) & & -.228 \\
& & .228 \\
& & $.200^{\mathrm{c}, \mathrm{d}}$ \\
\hline
\end{tabular}

a. Test distribution is Normal.

b. Calculated from data.

c. Lilliefors Significance Correction.

d. This is a lower bound of the true significance.

Pengujian hipotesis hasil analisis LKS dan analisis video diskusi tersebut menunjukkan rata-rata kreativitas matematis siswa lebih dari atau sama dengan 80 (KKM). Rata-rata skor kreativitas matematis siswa kelas XI MIPA 6 di SMA Negeri 2 Jember yaitu 83,33. Variabel kreativitas matematis siswa ini berada dalam kategori baik. Capaian skor yang baik tersebut disebabkan karena pembelajaran yang digunakan model Project Based Learning terintegrasi STEM. Hal ini sesuai dengan penelitian Ismayani (2016) bahwa, setelah pembelajaran STEM Project Based Learning kreativitas matematis siswa secara umum dinyatakan baik.

\section{SIMPULAN DAN SARAN}

Berdasarkan hasil penelitian dan pembahasan, dapat disimpulkan bahwa penerapan model Project Based Learning terintegrasi STEM dapat meningkatkan kreativitas matematis siswa kelas XI MIPA 6 di SMA Negeri 2 Jember. Uji hipotesis yang telah dilakukan menunjukkan bahwa ratarata kreativitas matematis siswa lebih dari atau sama dengan 80. Rata-rata skor kreativitas matematis siswa kelas XI MIPA 6 SMAN 2 Jember yaitu sebesar 83,33.

Saran yang dapat diberikan yaitu memastikan siswa bahwa mereka harus sudah benar-benar paham bagaimana mekanisme model pembelajaran yang digunakan agar siswa tidak kebingungan.

\section{DAFTAR PUSTAKA}

Ardi, A., Nyeneng, D.P., Ertikanto, C. 2015. Pengembangan Modul Pembelajaran

Alexander. 2007. Effect Instruction in Creative Problem Solving on Cognition, Creativity, and Satisfaction among Ninth Grade Studenta in an Introduction to World Agricultural Science and Technology Course. Texas Tech University.

Astuti, Siwi Puji. 2015. Pengaruh Kemampuan Awal dan Minat Belajar Terhadap Prestasi Belajar Fisika. Jurnal Formatif. Volume 5 (1):70

Badan Pusat Statistik Jakarta Pusat, 2010. Statistik Indonesia Tahun 
2010. Jakarta Pusat : Badan Pusat Statistik

Capraro, R. M., Capraro, M. M., Morgan, J. R., \& Slough, S. W. (2013). STEM Project Based Learning: $\quad A n$ Integrated Science, Technology, Engineering, and Mathematics (STEM) Approach .

Farwati, R., Anna, P., Harry, F., \& Tatang, S. 2017. Integrasi Problem Based Learning dalam STEM Education Berorientasi pada Aktualisasi Literasi Lingkungan dan Kreativitas. Prosiding Seminar Nasional Pendidikan IPA 2017. Halaman 202

Hanover Research (2011). K-12 STEM education overview.

Ismayani, Ani. 2016. Pengaruh Penerapan STEM Project Based Learning Terhadap Kreativitas Matematis Siswa SMK. Indonesian Digital Journal of Mathematics and Education. 3 (4):271

Jaedun, Amat. 2011. Metodologi Penelitian Eksperimen. Yogyakarta: LPMP

Kemendikbud (2013). Lampiran Peraturan menteri pendidikan dan kebudayaan Nomor 68 tahun 2013 tentang Kerangka dasar dan struktur kurikulum sekolah menengah pertama/madrasah tsanawiyah. Jakarta: Kemdikbud.

Kemendikbud. 2016. Materi Pelatihan Guru: Implementasi Kurikulum 2013 SMA/MA, SMK/MAK Matematika. Jakarta: Kemdikbud.

Reeve, E. M. (2013) Implementing science, technology, mathematics and engineering (STEM) education in Thailand and in ASEAN. Bangkok: Institute for the Promotion of Teaching Science and Technology (IPST).

Roberts, A. (2012). A justification for STEM education. Technology and Engineering Teacher. 74(8): $1-5$.

Siregar, Syofian. 2013. Metode Penelitian Kuantitatif. Jakarta: PT Fajar Interpratama Mandiri

Sugiyono, (2008). Metode Penelitian Kunatitatif Kualitatif dan $R \& D$. Bandung: ALFABETA

Tseng, K.-H., Chang, C.-C., Lou, S.-J., \& Chen, W.-P. (2013). Attitudes towards science, technology, engineering and mathematics (STEM) in a project-based learning (PjBL) environment. International Journal of Technology and Design Education. 23(1): 87102. 